\title{
FRANQUISMO, CÁRCEL Y PROPAGANDA: EL PERIODICO REDENCIÓN
}

\author{
FRANCOISM, PRISON AND PROPAGANDA: THE REDENCIÓN \\ PERIODICAL
}

DOI: http://dx.doi.org/10.15448/2178-3748.2015.1.18612

\author{
Gutmaro Gómez Bravo \\ Doutor em História - Universidad Complutense de Madrid \\ E-mail: ggomezb@ghis.ucm.es
}

\begin{abstract}
RESUMEN: El 1 de abril de 1939 aparecía el periódico Redención. Se ponía en práctica un nuevo estilo de propaganda destinado a cambiar la imagen de Franco. Desde el comienzo de la guerra, la cultura y el libro se habían convertido en un elemento fundamental en la batalla de las ideas. Se habían sucedido sin cesar las instrucciones para el control y la censura de libros, pero era la primera vez que se experimentaba la creación de un periódico como Redención, consagrado a mostrar la conversión de los propios presos políticos a través de su acceso a la información y la "lectura sana". El semanario Redención era un producto técnica e ideológicamente pensado y dirigido por los propagandistas católicos, con un fuerte y definido programa cultural que desde el final de la guerra fue potenciado como instrumento dirigido a la conquista de las "minorías selectas", en esta caso, hacia la "intelectualidad roja" para exhibir públicamente su arrepentimiento. Mostrar que en la España de Franco los presos aprendían a leer y escribir, y hasta hacer periódicos, tenía un claro objetivo: suavizar la dura imagen de la represión a la vez que desmitificar la labor pedagógica y el "proyecto cultural" republicanos. Un proceso cultural que se dirigió integralmente hacia el trabajo, la conducta y la instrucción, primaria y religiosa, esto es, hacia la redención de penas por el esfuerzo intelectual.
\end{abstract}

PALABRAS-CLAVE: Franquismo. Cárcel. Propaganda.

ABSTRACT: On 1 April 1939 appeared the periodical called "Redención". With it, came to be practiced a new style of propaganda, designed to change the image of Franco. Since the war began, the culture and the book had become a key element in the battle of ideas. The orders for the control and censorship of books had succeeded incessantly until then, but this was the first time they tried to create a periodical like Redención, aimed at spreading the conversion of political prisoners themselves through their access to information and "healthy reading". The weekly newspaper Redención was a product technically and ideologically conceived and directed by Catholic propagandists, with a strong and defined cultural program. Since the end of the war, the periodical was potentiated as a tool for the achievement of 'choicest minorities' - in this case, the left-wing intelligentsia - so that they publicly showed his repentance. Show that in Franco's Spain prisoners could learn to read and write and even learn how to make newspapers - had a clear goal: soften the harsh image of repression, while the Republican pedagogical work and your "cultural project" were demystified. A cultural process entirely directed to work, behavior and primary and religious instruction, ie, toward the mitigation of penalties due to the intellectual effort.

KEYWORDS: Francoism. Prison. Propaganda.

Para ellos fundaremos prensa especial, crearemos entidades editoriales, dispondremos una propaganda noble y digna. Declaraciones de Franco a Manuel Aznar, $1 \%$ ene/1939

${ }^{1}$ Reproducida en: El Diario Vasco, 1\%abr/1939, p. 1.

Oficina do Historiador, Porto Alegre, EDIPUCRS, v. 8, n. 1, jan./jun. 2015, p. 117-133. 
El 1 de abril de 1939, tres meses después de estas declaraciones, aparecía el periódico Redención y a grandes letras su titular: "Yo aspiro a ser el Caudillo de todos". 2 Se ponía en práctica un nuevo estilo de propaganda destinado a cambiar la imagen de Franco (SÁNCHEZ BIOSCA, 2002-2003). Desde el comienzo de la guerra, la cultura y el libro se habían convertido en un elemento fundamental en la batalla de las ideas. Se habían sucedido sin cesar las instrucciones para el control y la censura de libros, pero era la primera vez que se experimentaba la creación de un periódico como Redención, consagrado a mostrar la conversión de los propios presos políticos a través de su acceso a la información y la "lectura sana". A finales de febrero de 1939, la Jefatura Nacional de Prisiones lanzó un concurso entre los reclusos para formar los equipos que debían sacar adelante el periódico, anunciando que su colaboración sería tenida en cuenta como servicios prestados y rebaja en la condena. ${ }^{3}$

A pesar de que este uso de la lectura como forma de presión, colaboración y delación no tuviera precedentes en España, lo cierto es que la cultura impresa en prisiones no nacía por generación espontánea. Muchas de las personas que diseñaron el sistema de Redención de Penas por el Trabajo habían estado muy relacionadas con las tareas editoriales y propagandísticas anteriores a la guerra civil. La mayoría había pertenecido desde su creación a la ACNP (Asociación Católica de Propagandistas), y habían participado en la empresa de El Debate. Por encima de todos ellos destacaría, sin duda, José Sánchez de Muniain, secretario personal de Angel Herrera Oria, quien recibió el encargo de dirigir Redención4. Próximo a él dos figuras clave: el jesuita Pérez del Pulgar, que había sido el fundador del ICAI (Instituto Católico de Artes e Industrias) un centro con un importante desarrollo de las artes gráficas y las técnicas aplicadas al periodismo y Máximo Cuervo, propagandista del círculo de Madrid que editaría junto a Martín Artajo, los comentarios a Doctrina Social Católica, y ocuparía la Dirección General de Prisiones entre 1938 y 1942. Influencias que se extendieron más allá de la inmediata posguerra, a medida que crecía el peso de la familia tradicionalista en el ámbito de la Justicia Nacional.

\footnotetext{
${ }^{2}$ Redención fue publicado entre 1939 y 1977. Los ejemplares utilizados en la investigación se encuentran en la Hemeroteca Municipal de Madrid, signaturas 1939-1977. Más detalles sobre el periodico en: Gómez Bravo (2007; 2014).

3 “Esta Jefatura espera de V que emprenda una campaña inteligente y eficaz de propaganda entre los reclusos. Puede indicar también a los reclusos que la suscripción al semanario Redención será un acto que no quedará sin reconocimiento por parte de la Jefatura del Servicio de prisiones". Circular de 24/feb/1939.

${ }^{4}$ Posteriormente dirigió la revista Arbor y fue Director General de Enseñanza media con Ruiz-Giménez. En 1956 coincidiendo con su centenario preparó la Antología de Menéndez Pelayo (Tomos 155 y 156 de la BAC, 2500 páginas). En 1963 colaboró en la edición de las Obras Selectas de Angel Herrera Oria (BAC n 233).
}

Oficina do Historiador, Porto Alegre, EDIPUCRS, v. 8, n. 1, jan./jun. 2015, p. 117-133. 
El semanario Redención era un producto técnica e ideológicamente pensado y dirigido por los propagandistas católicos, con un fuerte y definido programa cultural que desde el final de la guerra fue potenciado como instrumento dirigido a la conquista de las "minorías selectas", en esta caso, hacia la "intelectualidad roja" para exhibir públicamente su arrepentimiento. ${ }^{5}$ Mostrar que en la España de Franco los presos aprendían a leer y escribir, y hasta hacer periódicos, tenía un claro objetivo: suavizar la dura imagen de la represión a la vez que desmitificar la labor pedagógica y el "proyecto cultural” republicanos (MARTÍNEZ RUS, 2011). Un proceso cultural que se dirigió integralmente hacia el trabajo, la conducta y la instrucción, primaria y religiosa, esto es, hacia la redención de penas por el esfuerzo intelectual.

\section{La redención de penas por el esfuerzo intelectual}

La idea de que los presos redimieran condena a través de la lectura surge al cumplirse un año de la sublevación del 18 de julio (LA NORMATIVA LABORAL Y PENITENCIARIA, 1982, p. 36-40). No obstante, no fue incluida en las disposiciones de la Junta Técnica del Estado hasta la edición del Decreto de Redención de Penas por el Trabajo, de 7 de noviembre de 1938, que tenía su inmediato precedente en la circular de 28 del 5 de 1937 "sobre trabajo remunerado de los prisioneros de guerra y presos por delitos comunes". Posteriormente, la normativa de guerra se incorporó al ordenamiento penal común para mitigar las largas penas privativas de libertad que resultaban de la aplicación del Código de Justicia Militar de 1890 a los condenados por rebelión militar (RODRÍGUEZ DEVESA, 1973, p. 106). Pero no todos los presos eran beneficiarios de la redención. Sólo aquellos con condena firme podían acogerse a ella. Los encausados por el Tribunal para la Represión de la Masonería y el Comunismo tampoco podían hacerlo por ser considerados "sujetos no aptos de corrección",6.

En cuanto a las presas, la distinción en el trato y en la consideración delictiva de la mujer hacía que en ella el trabajo fuese obligatorio e inherente a la corrección femenina, mientras que en el caso masculino el trabajo era beneficio penitenciario. Finalmente, al

\footnotetext{
${ }^{5}$ Sobre el concepto de ideología y otras referencias teóricas utilizadas, ver Foucault (1999) y Judt (2008).

${ }^{6}$ También quedaban excluidos del régimen de redención de penas por el trabajo aquellos que intentaban evadirse y a los condenados que con posterioridad a su condena cometieran un nuevo delito. Orden de 14/mar/1939. BOE n. 77 de 19/jun/1939.
} 
crearse los establecimientos especiales de reforma para mujeres caídas, se excluía de la redención de penas a las mujeres por el esfuerzo intelectual, si bien también organizarían escuelas y talleres ${ }^{7}$. Se llega a una cierta igualación sobre la necesidad de instrucción con la aprobación del Decreto de 8 de febrero de 1946 de Reglamentación Orgánica del Trabajo Penal intramuros. Los reclusos de ambos sexos estaban obligados a adquirir un nivel mínimo de instrucción. La redención por el esfuerzo intelectual, que se aprobaría en el decreto de 23 de noviembre de 1940 "concedía el beneficio de la redención de penas a los condenados que durante su estancia en prisión lograsen instrucción religiosa o cultural”. Según esta norma se reducirían dos, cuatro o seis meses de condena a aquellos que obtuviesen la aprobación del conocimiento de la religión en sus grados elemental, medio o superior respectivamente. La redención por la instrucción religiosa y cultural suponía, "desarrollar el principio y la labor de rescate" designando para ello los instrumentos principales de formación: religiosa, cultural y patriótica ${ }^{8}$.

En enero de 1939 se anuncia el programa del semanario Redención, el periódico de los presos y sus familias: sería semanal, de tamaño semejante a los diarios grandes, y de 8 páginas "bien nutridas de información y de lectura amena. Será además el único periódico que podrán leer los presos" ${ }^{\text {. }}$. Costaría dos pesetas el trimestre pero no se vendería suelto sino por suscripción. Este sería, sin duda, su elemento más importante ya que designaba sus dos objetivos prioritarios: la colaboración de los propios reclusos con experiencia literaria y periodística por un lado y la suscripción como elemento claramente distintivo de la buena conducta del resto. Máximo Cuervo declaró que se trataba de alcanzar que los presos mirasen al periódico como "cosa propia", cumpliendo "la norma general de toda propaganda bien orientada que exige que ésta se lleve a cabo por individuos pertenecientes a la misma comunidad a la cual se dirigen" ${ }^{\prime \prime}$.

Un periódico pensado como una herramienta para dividir y aislar a los presos políticos a través de su participación en el propio aparato de la propaganda de prisiones, con un programa muy definido de antemano. Debería ser ameno, contar información general de España y del extranjero, incluir reportajes y fotos. Debería tener otras secciones que incluyeran la relación de ofertas de trabajo, la lista de jornales pagados, la legislación penal que fuera apareciendo, así como de avisos, permisos de comunicación, paquetes, noticias de

\footnotetext{
${ }^{7}$ Decreto 06/nov/1941 (art. 5).

${ }^{8}$ Orden de 23/nov/1940 y circular de 05/ene/1941.

${ }^{9}$ La prohibición de la lectura de prensa derogaba la Orden de 22/abr/1931 por los internos, a excepción de los incomunicados por disposición judicial y de los que sufrieran castigo de aislamiento, pudieran "recibir y leer toda clase de prensa" (HERRERO HERRERO, 1985, p. 382).

${ }^{10}$ Redención, n. 1, p. 2.
}

Oficina do Historiador, Porto Alegre, EDIPUCRS, v. 8, n. 1, jan./jun. 2015, p. 117-133. 
indultos y revisiones de causas " todo lo que en suma pueda orientar a reclusos y sus familias ${ }^{11} \%$ Las familias eran el punto culminante de este plan de reeducación que doctrinalmente trataba de conseguir que el preso volviera a la sociedad transformado en "un cristiano, en un español y en un trabajador perfecto". Para ello, en enero de 1939, la redención de penas ya estaba legalmente vinculada a la libertad condicional. Nadie saldría de la cárcel sin haber pasado por una de sus fases, y, lo que fue más importante para la consecución del ideal de paz social franquista, el futuro del preso quedaba vinculado a su disposición para colaborar y a la de los miembros de su familia.

De este modo, el radio de acción del sistema penal no quedó localizado en lo judicial, se extendió a todo el campo social de una política represiva que ocupó tanto el espacio público como el privado. La colaboración presentaba una serie de incentivos muy significativos del plan de reeducación social que diseñó el franquismo. El mensaje dirigido a los presos, hay que insistir, era claro: si trabajaba podría estar más cerca de la familia, tendría acceso a más visitas, mejora de la comida y progresiva reducción de la condena. En una palabra, podría sobrevivir (GÓMEZ BRAVO; MARCO, 2011).

Para facilitar las colaboraciones del periódico se abrió un concurso sobre las materias siguientes: la primera sección, sobre caricaturas y dibujos humorísticos, preferiblemente en forma de historieta. Una segunda dirigida a dibujos artísticos y viñetas periodísticas que ilustrase el texto del semanario, y por último, un concurso para escritores y periodistas, entre reclusos periodistas y de profesiones liberales sobre las siguientes especialidades:

a) Cuentistas, un cuento con libertad de tema y de no más de 8 cuartillas pequeñas.

b) Cronistas, una crónica o reportaje sobre temas en la vida de las prisiones, tomando como base libremente un hecho o noticia cualquiera. En estilo sobrio, informativo y periodístico. El tema podrá ser: la lectura (si la hubo en esa prisión), el día 1 de enero de 1939, de los nombres de los condenados a muerte indultados por el Caudillo; la impresión y comentarios producidos por algún parte de guerra importante, la labor del patronato en esa prisión (...). Puede tomarse también como tema algún suceso presenciado en la zona roja.

c) Humoristas, una crónica en broma de la vida en las prisiones, ejemplo, "ecos de sociedad", anecdotario, historia de tipos graciosos, recuerdos en broma de la zona roja, etc...

d) Articulistas. Un artículo sobre los temas siguientes:

1. La misión providencial de España.

2. Lo que espero del Patronato Central para la Redención de las Penas por el Trabajo (sugestiones inspiradas por la lectura de la orden de 7 de octubre de 1938).

${ }^{11}$ Oficio-circular de 08/feb/1939. Para la intervención de distintas formas en la creación de significado, cf.: Sánchez García (2005, p. 57-86).

Oficina do Historiador, Porto Alegre, EDIPUCRS, v. 8, n. 1, jan./jun. 2015, p. 117-133. 


\section{La reforma que exige la Nueva España en el individuo. ${ }^{12}$}

Cada caricatura, dibujo o artículo publicado equivaldría a dos días de trabajo y, además, el director del periódico podría escoger entre ellos a sus colaboradores asiduos que pasarían a ser asimilados a trabajadores con destino fijo, algo muy importante para la vida en prisión y para salir de ella. Las obligaciones de los denominados "corresponsales informativos" irían encaminadas a enviar noticias detalladas "de todos los actos que ocurran e la prisión", pero la lista también estaba ya definida de antemano: incluía actos religiosos y patrióticos, apertura de escuelas y talleres, colocación de reclusos, festividades, acogida del semanario Redención, comentarios preferentes de la población reclusa etc. más difusas era sin embargo, las tareas administrativas de los responsables del periódico en cada cárcel, ya que además de llevar la lista de altas y bajas de los suscriptores, debía conseguir "la colaboración espontánea de los demás reclusos", de acuerdo a las instrucciones del director. Si no conseguían suscripciones, no obtendrían la libertad condicional, ese era el precio.

El periódico nacía para sustituir la imagen de dureza de las prisiones por el carácter benéfico dado al sistema de redención. De ahí que al lado de cada disposición de naturaleza legal relativa a aspectos como el trabajo o la libertad condicional, existiera otro de corte cultural $^{13}$. Comenzaba "la Cruzada de divulgación ético-moral sobre las masas", como la definió el Ministro de Educación Ibáñez Martín. Este programa de actividades religiosas y culturales, surgido directamente de la guerra y puesto en marcha desde principios de 1939, terminó imponiéndose como reglamento de prisiones. El recluso que deseara realizar una producción artística, literaria o científica lo debía comunicar al maestro del establecimiento. La Junta de Disciplina de cada centro pasaría al Patronato Central de Redención de Penas por el Trabajo, un informe sobre la cuantía de redención que a su juicio merecía, "siendo requisito preciso para lograr redención de pena por estos trabajos que el autor tenga aprobado el grado superior de religión", por eso las figuras fundamentales en su desarrollo fueron los maestros de primaria y los capellanes ${ }^{14}$.

\footnotetext{
${ }^{12}$ Circular de 08/mar/1939.

${ }^{13}$ En septiembre de 1939, fueron creadas las Colonias Penitenciarias Militarizadas, el mismo mes que se inauguraba la biblioteca circundante de la Prisión de Oviedo. Por entonces ya se cifraban en 400 las reclusas que recibían instrucción en la prisión de Ventas, y se daba luz verde a las sesiones de cine, proyectándose el primer pase en la prisión de Porlier el 21 de octubre. Redención, n. 26, de 23/sep/1939.

${ }^{14}$ El artículo 99 del Código Penal de 1944 incorporaba estos cuatro supuestos para la redención de penas por el esfuerzo intelectual: a) Por cursar y aprobar las enseñanzas; b) Por tomar parte en actividades artísticas y culturales; c) Por desempeñar destinos de carácter intelectual. Por producciones originales de carácter científico, literario o artístico (CASTEJÓN, 1946, p. 4-6).
} 
Los primeros datos oficiales sobre tirada y suscriptores del periódico eran impresionantes. Entre el tercer trimestre de 1939 y el de 1940 casi se ha multiplicado por tres el número de ejemplares, pasando del millón de ejemplares en marzo de 1940.

Tabela 1: Total ejemplares Redención por trimestre

\begin{tabular}{lllll}
\hline $1^{\circ}$ & & & 1940 & 921.400 \\
$2^{\circ}$ & 1939 & 332.300 & 1940 & 1.032 .600 \\
$3^{\circ}$ & 1939 & 491.800 & 1940 & 1.116 .000 \\
$4^{\circ}$ & 1939 & 682.500 & 1940 & 1.039 .200 \\
\hline
\end{tabular}

Fuente: Dirección General de Prisiones.

Un mes después empezó a insertarse color en las páginas de Redención. La propaganda acerca de los progresos del Nuevo Estado por evangelizar e instruir a los presos seguía un ritmo ascendente. ${ }^{15}$ A partir de abril de 1940 Redención publica una cartilla para los reclusos analfabetos que aparecía cada sábado con las materias que se consideraban abarcables durante la semana. El 5 de agosto de 1939 fueron inaugurados los talleres penitenciarios de Alcalá de Henares. La cuna de Cervantes, la Universidad obra cumbre de Cisneros, la Biblia Políglota y la trascendencia en las celebraciones anteriores de la Fiesta del Libro fueron las razones oficiales para este emplazamiento, pero en realidad, los talleres de impresión en el presidio de Alcalá existían desde tiempo atrás, fruto de la evolución de los talleres para reclusos menores y otros tratamientos correccionales que se experimentaron en las prisiones de la vieja ciudad complutense (GÓMES BRAVO, 2005; 2006).

La propaganda aireó la ampliación e importancia de estos talleres de impresión y encuadernación. Aquellos reclusos que en la vida civil hubieran desempeñado su oficio en las artes gráficas podrían redimir pena allí en consideración de destino fijo. Pérez del Pulgar, ingeniero especialista en electrodinámica, fue su principal impulsor. Su experiencia a partir de 1912 en el Instituto Católico de Artes e Industrias (ICAI), inspirado en un centro de jesuitas de Lille, estuvo muy presente en los talleres de Alcalá. Allí se intentó reproducir la memoria de un centro creado inicialmente para moralizar hijos de obreros, consolidado en escuela técnica, que pasaría a ser Universidad Católica en 1918. A partir de 1941, los talleres de Alcalá centralizaban la producción gráfica penitenciaria de toda España. A principios de 1943 de estos talleres salían revistas como Guión, Comunicación o Arte y Letras. La publicación de obras de gran tirada para el Estado, como los catecismos oficiales, el Plan General de Obras

\footnotetext{
${ }^{15}$ En diciembre de 1940 se destacaba el caso de un analfabeto, manco de las dos manos, que aprendió a escribir en el viejo presidio valenciano de San Miguel de los Reyes. Redención, n. 89, p. 4.
} 
Públicas de 1950, la Biografía de París en edición de lujo, y, sobre todo, la Biblioteca de Autores Cristianos, que asegurarían el trabajo en estos talleres durante toda la dictadura.

\section{La Biblioteca Particular del Preso}

De forma similar al periódico y a las tareas culturales inscritas en el sistema de redención de penas, fue creada la Editorial Redención. El punto decisivo para la configuración de la editorial, el proyecto estrella de Sánchez de Muniain, vendría del cruce con Ediciones Jerarquía, de la Falange navarra, que a partir de 1941 pasó a ser Editora Nacional. Dirigida a partir de 1943 por Laín Entralgo, que llegaría a publicar un ensayo sobre el trabajo en la propia Biblioteca de Redención, Editora Nacional se editaría también en estos Talleres Penitenciarios de Alcalá de Henares. El plan editorial era el de publicar libros baratos (una peseta para el suscriptor) con el objeto de que el recluso español pudiera tener "su biblioteca particular". Se empezó publicando una obra al mes. Para ello, Sánchez de Muniain, diseñó otro concurso entre presos para formar un "florilegio de poesías desde la celda". Al igual que en el periódico, se indicaba la temática: religiosa, la Patria (las ideas, la tierra, los hombres) y varia. Según Muniain, "la prisión podía ser muy propicia para la sensibilidad poética"16.

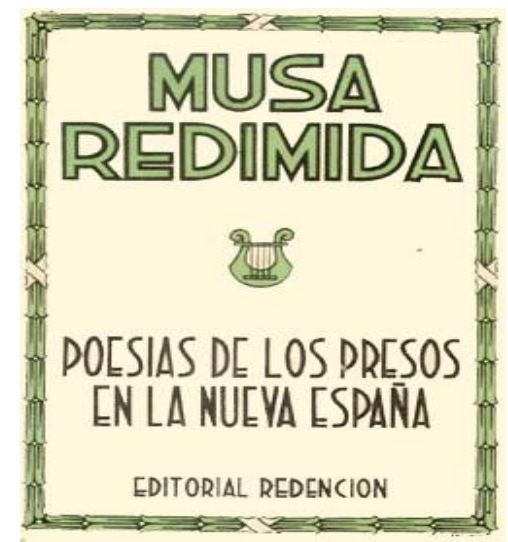

Figura 1: Laus Deo Virginique Matri. Precio, una peseta; tirada, 30.000 ejemplares. Portada de Musa Redimida. Editorial Redención, 1940, Madrid.

\footnotetext{
16 "Este recogimiento, tan provechoso a toda alma no demasiado encallecida, y la tensión del espíritu, excitan de tal manera las facultades intelectuales del preso y su sensibilidad estética, que los poetas medianos hacen cosas buenas y los simples artesanos labran imágenes de arte". Prólogo de Musa Redimida donde continua "El arte en las prisiones es el cauce por donde deriva la amargura acumulada en cada individuo, pues todo preso lleva consigo un drama. Es misión del Patronato, en este orden, conducir ese caudal riquísimo de sensibilidad estética y moral, superando la fría fórmula del Arte por el Arte, que si es muy discutible en el Arte mismo, estudiado sin Dios y sin Patria, es totalmente falsa aplicada a la economía de los pueblos". Prólogo a Musa Redimida.
}

Oficina do Historiador, Porto Alegre, EDIPUCRS, v. 8, n. 1, jan./jun. 2015, p. 117-133. 
Este fue el plan de la obra de la Editorial Redención de 1940: Franco, de J. Arrarás (30.000 ejemplares), Musa redimida (Versos de los reclusos de la Nueva España), José Antonio: su ideario (30.000), Los atrayentes problemas de la moderna astronomía, por el Padre Romañán, director del Observatorio del Ebro (30.000), La fundación de un imperio. España en América por Ciriaco Pérez, Catedrático de Historia Universal de Madrid (30.000). Junto a estos primeros títulos se editaron el Catecismo en primer y segundo grado, del Cardenal Gasparri, así como dos textos de Solana, Primeras lecturas y Enciclopedia, del grado elemental (15.000) y medio (10.000) para la instrucción primaria en las prisiones ${ }^{17}$.

El resto del plan se concretaba en dos secciones, una elemental y de oficios y otra general dividida en varias series. Para la instrucción primaria y el adiestramiento de oficios se pensaron títulos como: Gramática, ortografía y normas de redacción, Aritmética y elementos de contabilidad, Nociones de Geometría, Geografía e Historia de España, Manual del Electricista y del Montador, Cultivos de secano y regadio, El tipógrafo y el linotipista o La cría de animales domésticos.

La primera de las series generales era la Apologética. Dirigida por profesores del Colegio Máximo de Oña se compuso de: Necesidades de la religión y causas de la irreligión, La existencia de Dios, El origen del mundo y la vida, Jesús de Nazaret y Las credenciales de Jesucristo. La segunda serie llevaba el epígrafe de Política y sociedad. Su primer título era La doctrina nacionalsindicalista de Emiliano Aguado, Por la Patria, el Pan y la Justicia, de Jesús Arcilla (exdirector de Solidaridad Nacional), Espíritu de Valladolid, por Antonio Tovar (Director General de Enseñanza Profesional), El hombre y el trabajo, por Pedro Laín Entralgo (Director del Departamento Ediciones Ministeriales) y la Misión redentora del fuero del trabajo, que se encontraba en preparación.

La tercera serie, de Historia, comenzaba con Las cárceles de la Inquisición, del Padre Llorca (historiador), Sabiduría y hazañas de Hernán Cortés, por Carlos Pereyra (hispanista) seguidas de tres títulos de Catedráticos de Historia Universal de la Universidad de Madrid: $E l$ nacimiento de la nacionalidad española, de Santiago M Díaz, Justicia y trabajo en la España del siglo XVI de Carmelo Viñas y Felipe II, Emperador de la Cristiandad por Santiago Magariños.

La serie científica sólo tenía dos títulos, Curiosidades de la física moderna, de Julio Palacios, Catedrático Universidad de Madrid, y la Evaluación técnica de la edificación, por

\footnotetext{
17 “Edición autorizada por la Editorial Escuela Española, Hijos de Ezequiel Solana, para la venta exclusiva en establecimientos penitenciarios" (OBRA PATRONATO REDENCIÓN PENAS POR EL TRABAJO, 1943, p. $15)$.
} 
Julio Prieto, Ingeniero de Caminos. El último grupo correspondía a la serie literaria, con títulos clásicos del Siglo de Oro y obras de gestas medievales e imperiales: Romances de la pasión y sonetos espirituales, de Lope de Vega, El Cid en boca del pueblo. Antología de la poesía heroico-popular, la Crónica de la conquista de Méjico, de Bernal Díaz del Castillo, El príncipe constante, de Calderón de la Barca y La prudencia en la mujer, de Tirso de Molina.

El primer volumen, editado por la librería Santarén de Valladoli, de Publicaciones Redención, fue el primer esbozo de esta colección destinada a formar la biblioteca particular del preso y a editarse por los propios presos en los talleres penitenciarios de Alcalá. Un proyecto cuya utilidad ya fue ensalzada en La solución que España da al problema de sus presos políticos, donde Pérez del Pulgar describía las tareas necesarias para el importante capítulo de la redención espiritual y social del recluso de la siguiente manera: "el cuidado de nutrir las bibliotecas de los penales con los libros, folletos y revistas. La idea de organizar la lectura en común, que la experiencia va acreditando como medio utilísimo para multiplicar la eficacia de la biblioteca" ${ }^{\text {"18 }}$. Un "cuidado" que se resumía en la práctica en la censura y el control previo de las lecturas que quedaban reguladas también bajo la Prensa y Propaganda de Sánchez de Muniain ${ }^{19}$.

Durante el verano de 1939, el periódico ya se hacía eco de las tareas de difusión cultural como eran definidas. La Prisión Escolapios de Bilbao recibió un donativo de 100 libros por parte de las damas de Acción Católica y dieron comienzo las clases para analfabetos en la prisión de Soria a las que "los reclusos asisten con verdadero interés" 20 . En cuanto a la biblioteca, "se ha hecho preciso establecer turnos". La escuela en la Prisión celular de Vitoria continuaba "su marcha triunfal", mientras que en la biblioteca de la prisión provincial de Larriñaga (Bilbao) "ya sólo abundan los libros de carácter instructivo así como las novelas de sana moral”. El número 14 de Redención de primeros de julio de 1939, resaltaba una noticia de la prisión de Burgos, en la que, tan sólo después de unos meses, los reclusos que asistían a clase ya no necesitaban ayuda para escribir cartas, dando por

\footnotetext{
${ }^{18} \mathrm{Al}$ valorar las virtudes de la lectura en prisión en el nuevo contexto de pacificación de España y, se refería concretamente a la experiencia del fascismo italiano de trabajos con presos en colonias para habitaciones baratas de Littoria o Carbonia, donde la lectura en común había sido el principal vehículo de reeducación cultural (PÉREZ DEL PULGAR, 1939, p. 48).

19،Comunícole que desde la fecha no podrá ser comprado para la biblioteca ningún libro, ni tampoco entregado para su lectura ningún otro que llegue a los reclusos por conducto particular, si previamente no fueron autorizados por el Patronato Central para la Redención de Penas por el Trabajo o sus delegados”. Máximo Cuervo. Vitoria 31 de diciembre de 1938, III Año Triunfal. Jefatura Nacional de Prisiones.
}

${ }^{20}$ Redención, n. 12, 17/jun/1939, p. 5.

Oficina do Historiador, Porto Alegre, EDIPUCRS, v. 8, n. 1, jan./jun. 2015, p. 117-133. 
exterminado totalmente el analfabetismo dentro de la prisión. Una semana después se detallaba el envío de 150 libros a la prisión de Málaga así como la llegada de las "lecturas del soldado" a la prisión provincial de Lugo. A principios de 1940 las "noticias literarias" comienzan a ser más detalladas. Se da cuenta de la biblioteca de Torrijos (Toledo), con 1500 ejemplares agrupados en secciones de "agricultura, artes y oficios, ciencias naturales, comercio y finanzas, Derecho, Geografía e Historia, Ingeniería y Construcción, literatura, medicina, a parte de la literatura circundante a base de la literatura y cultura general” ${ }^{\text {21 }}$.

La versión oficial sobre el libro más leído en las bibliotecas de prisiones fue unánime durante mucho tiempo: El Quijote. El resto de los títulos más solicitados fueron (siguiendo el orden suministrado por la jefatura de prensa y propaganda): El siglo de las misiones, El sombrero de tres picos, El Nuevo Testamento, La divina comedia, Quo Vadis? y la Colección de discursos de José Antonio (OBRA PATRONATO REDENCIÓN PENAS POR EL TRABAJO, 1943, p. 23). En marzo de 1943 el número de volúmenes en las bibliotecas de prisiones excedía de 35.000. El libro más leído seguía siendo El Quijote "lo que prueba el depurado gusto literario de nuestros lectores, sobre todo si se tiene en cuenta que en el fondo de libros de las bibliotecas los hay de aventuras y de simple pasatiempo"22.

El esfuerzo de la propaganda estaba también basado, además de la sistematización y centralización de la información, en la difusión de noticias de impacto en la vida civil de la España de postguerra, como la Fiesta del Libro. El día anterior a la primera fiesta del libro después de la guerra, los directores de prisiones recibieron un telegrama para "cooperar en la fiesta del libro" ${ }^{23}$. Y una semana después, Redención abría con un retrato de Cervantes y un titular El libro y su fiesta ${ }^{24}$. Año tras año el semanario publicó noticias del día del libro en las prisiones. Con motivo de la Fiesta del Libro Español de 1943 el maestro de la prisión provincial de Córdoba dio una conferencia titulada "El libro como perfeccionamiento moral del hombre". Como ejemplo de qué tipo de lecturas conducían a este fin, los reclusos leyeron fragmentos de El Quijote, Los nombres de Cristo y La Dorotea.

El Día del Libro, también fue el motivo principal para la organización de concursos literarios y poéticos entre los reclusos, a los que se les entregaba diplomas de honor y premios en metálico. El Instituto Nacional del Libro, “que resolverá cuantos problemas afecten a esta

\footnotetext{
${ }^{21}$ Redención, n. 45, 17/feb/1940.

${ }^{22}$ Redención, n. 208, de 20/mar/1943, p. 3.

23 "Póngase de acuerdo con patronato archivos y bibliotecas para cooperar a la fiesta del libro y cobrar la cuarta parte recaudación destinada a bibliotecas de prisiones que v girará después al patronato".

24 "Pensamos también los presos en este tema actual que nos brinda la Fiesta del Libro. El nos ha demostrado (Cervantes) que la limitación de las libertades corporales determina una mayor libertad del alma, y el ejercicio de una de sus mayores virtudes: la reflexión”. Redención, n. 5, de 29/abr/1943, p. 8.
} 
industria", suministraba los datos y Redención ofrecía su interpretación. El balance de la producción editorial en España del primer semestre de 1943 era un auténtico hito después del mazazo de la guerra; se hablaba del esplendor de la actual edición española y del pleno rendimiento de los talleres especializados de Barcelona, culminando con cifras este idílico panorama editorial: "2673 libros en seis meses suponen el doble de la producción editorial media durante el lustro 1931-1935,25.

Las autoridades insistían en la circulación la idea de la reactivación de los circuitos culturales, la guerra había pasado, en España había editoriales y libros, y en las prisiones también.

Tabela2: Producción editorial española primer semestre 1943

\begin{tabular}{ll}
\hline Obras generales & 416 \\
Filosofía & 48 \\
Teología y Religión & 165 \\
Ciencias sociales y Derecho & 319 \\
Filología y linguiística & 63 \\
Ciencias Puras & 92 \\
Ciencias aplicadas & 253 \\
Bellas Artes & 176 \\
Literatura & 875 \\
Historia y Geografía & 266
\end{tabular}

Fuente: INLE. ${ }^{26}$

La instrucción "religiosa, patriótica y cultural" había conseguido "desterrar" el analfabetismo (menos de un 2\% según las cifras de 1943) en menos de 5 años. Según las memorias de la Obra de Redención, cerca del 99\% de los presos que habían entrado en prisión durante o al finalizar la guerra civil no habían visto nunca las primeras letras. El contrapunto de las cifras oficiales lo pone aquí el descenso, por diferentes vías, de la población penal; un descenso continuado hasta 1945 al que parece adecuarse la tirada de Redención, que en tan sólo tres años vio reducida sensiblemente su tirada a algo más de la mitad ${ }^{27}$. Mientras tanto, el número de volúmenes de las bibliotecas de prisiones seguía un aumento espectacular, que

\footnotetext{
25 M. C., J. Ojeada a la industria editorial. Redención, n. 231, de 28/ago/1943. Los nombres de algunos columnistas y colaboradores siguieron sin ser revelados durante mucho tiempo.

${ }^{26}$ Redención, n. 231, de 28/ago/1943. Dos aclaraciones al cuadro: de las 416 obras generales, casi la totalidad iba destinada al público infantil; en el apartado de Historia y Geografía, 150 títulos eran en realidad biografías.

${ }^{27} 58.400$ volúmenes en 1943 y 37.800 en 1944. La diferencia con las tiradas de 1939-40, que sobrepasaban el millón, era justificada por la reducción de la población penal tras la concesión de 57.549 libertades condicionales (OBRA DE LA REDENCIÓN DE PENAS, 1944, p. 19-21).
} 
añadido al descenso de la población penal, disparaba los ratios de lectura en las prisiones (173.019 en 1944). La central de Barcelona seguía estando a la cabeza de las bibliotecas mejor dotadas, seguida por las prisiones de Burgos (central), Córdoba, Pamplona, Oviedo, Madrid y Valladolid. La obra de Cervantes seguía siendo la más solicitada, las andanzas del Ingenioso Hidalgo, y La Gitanilla, seguida de Orientaciones de la cultura española del “insigne polígrafo Menéndez y Pelayo", aunque ya se admitía la presencia "importante” de las obras "de simple pasatiempos y de aventuras".

Las cifras oficiales de la Obra de Redención de Penas de 1945 hablan de 65.170 reclusos que han redimido pena por el esfuerzo intelectual ${ }^{28}$. A partir de entonces, toda la información gráfica aparece recogida bajo el epígrafe de Misión religiosa. Labor cultural. Prensa y propaganda, donde se reconoce el papel del libro como "elemento auxiliar" de propaganda. La información sobre la misión cultural incorpora también los autores predilectos para representar obras teatrales por los reclusos: Calderón, Lope de Vega, Cervantes, Tirso, Jacinto Benavente, Pemán y los hermanos Alvárez Quintero (OBRA DE LA REDENCIÓN DE PENAS, 1945, p. 46).

A partir de 1945, las actividades culturales siguen ya el rígido orden estipulado en la instrucción de redención por el esfuerzo intelectual, donde puede verse que el papel de la lectura en común y del libro son fundamentales para lo que se definía como "complemento de la enseñanza del penado". En la organización del tiempo de los actos “culturales, artísticos y deportivos", puede vislumbrarse ya la importancia de la radio y el cine, de la siguiente manera:

$$
\begin{aligned}
& 1^{\text {o }} \text { - Lectura en común; } \\
& 2^{\text {o }} \text { - Cursos y conferencias especializadas; } \\
& 3^{\text {o }} \text { - Gimnasia y deportes; } \\
& 4^{\text {o }} \text { - Bandas de música y orfeones; } \\
& 5^{\circ} \text { - Audiencias radiofónicas; } \\
& 6^{\circ} \text { - Proyecciones cinematográficas; } \\
& 7^{\text {o }} \text { - Recreos dominicales. }
\end{aligned}
$$

Como en tantos otros aspectos, la concepción de la lectura en común en prisiones parece más propia del siglo XIX donde "la lectura en voz alta venía acompañada de una

\footnotetext{
${ }^{28} 11$ millones de días redimidos, 28 millones de jornales y 29.000 libertades condicionales, 9.000 niños acogidos al Patronato, 10.000 conferencias religiosas y 12 matrimonios entre reclusos. La estadística se realiza de forma mensual, por ejemplo en octubre de 1942, según el Patronato, redimieron pena 24.592 presos y en diciembre 23.792. En marzo de 1943 el número de los acogidos a la redención había descendido a 22.861 .
} 
proyección didáctica" 29 . La diferencia principal con el tiempo de la posguerra fue el grado propagandístico que alcanzó la lectura a viva voz para la que acabaron instalándose radios y altavoces. En la modelo de Valencia, existía inicialmente un equipo de lectores en común que leían a secciones de unos 1000 presos durante 40 minutos. Se hacía en horas de descanso y se escogían obras de la propia biblioteca, en las que al parecer destacaron las obras completas de Tihamer Thot ${ }^{30}$.

\section{Conclusión}

Vinculados desde muy pronto a la libertad vigilada y por tanto a la buena conducta en el cumplimiento de condena, la religión, la escritura y la lectura fueron las materias evaluables para la revisión de las sentencias a más de medio millón de presos procedentes de la guerra civil. La colaboración en cualquiera de las obras intelectuales, los libros y la cartilla de Redención serían sin duda una buena señal de esa transformación que el régimen de prisiones esperaba del recluso para devolver a "la buena España a los presos que así lo desearan". La denominada propaganda cultural y artística, se asentaba en la utilización de artistas e intelectuales "arrepentidos". El propagandista católico clave en este frente fue José Sánchez de Muniain; adaptó el mensaje teológico y jurídico de la redención a la vida en prisiones, reforzando la idea y el método de conversión a través de la especialización y el aislamiento individual. La consolidación de las prisiones de los años 40 no puede entenderse sin este anhelo de mostrar a los intelectuales arrepentidos y a los obreros convertidos trabajando para el régimen. Para ello se creó Redención, “el periódico de los presos y sus familias", que el propio Muniain destacaba como "un arte generativo de amor al contrario" (SÁNCHEZ DE MUNIAIN, 1946, p. 205-246).

La lectura, la escritura y la religión, en distintos grados, fueron las materias evaluables para acceder a la libertad condicional en aquellas penas menores. Pero no fueron puertas automáticas de salida, ya que la libertad vigilada terminaría siendo el elemento principal de censura y presión social de posguerra. Los Servicios de Vigilancia y Tutela se construyeron

\footnotetext{
29 "Y de hecho era la forma de enseñanza de la lectura por definición” (MARTÍNEZ MARTÍN, 2005, p. 15-34).

${ }^{30}$ Tras la instalación en 1941 del equipó radiofónico, el destino quedó reducido a un solo lector y dos suplementos (ayudantes). Memoria Cárcel Modelo de Valencia, 1942, p. 238. El destino de "lector", redimía condena por el esfuerzo intelectual (en alguna estadística se refiere a este destino y no a las lecturas).
}

Oficina do Historiador, Porto Alegre, EDIPUCRS, v. 8, n. 1, jan./jun. 2015, p. 117-133. 
básicamente sobre las redes locales. Las autoridades de este nivel emitían informes sobre la conducta moral, política y social de los que habían pasado por la cárcel o habían sido investigados por alguna jurisdicción especial. Una red que alcanzaba a la familia entera, que fue perfeccionándose y dotándose de más medios hasta su disolución en 1954. Los poderes locales se adaptaron sumamente bien a sus nuevas funciones, especialmente a la hora de confeccionar denuncias e informes de conducta, muchas veces incriminatorios acerca de la actividad intelectual del recién liberado. La novedad fue el poder que recibieron para decidir sobre el destino de los que salían en libertad vigilada, desde la manutención de su familia a la fijación de su residencia. En definitiva, quien terminaba valorando la peligrosidad del delincuente era el alcalde, el jefe de Falange, el párroco o la guardia civil, aunque también podían participar otras destacadas personas de la vida local, como ricos propietarios o empresarios que empleaban a presos, y aquellos "elementos femeninos especialmente caritativos".

Todos ellos formaron parte de estas comisiones encargadas de permitir que los rojos volvieran y se reintegraran en la vida local. La denegación sistemática del retorno llegó a tener tal magnitud que el Ministerio de Justicia terminó por sustituir las denegaciones por destinos a 250 kilómetros del pueblo natal. El destierro podía poner fin así a una larga nómina de castigos pero de ningún modo suponía un punto y final. Durante la segunda mitad de los años 40, el grueso de la política represiva se había desplazado hacia el poder local, donde se ejercía la más dura de las medidas económicas: la ley del mercado negro. La represión del estraperlo también recayó en la jurisdicción militar y en la Fiscalía de Tasas, pero sólo descabezó sus niveles más bajos, mientras que los más altos eran premiados con la política de precios o el reparto de las concesiones estatales con las que acumularon buena parte de sus capitales industriales y agrícolas.

Una red extendida por todo el país que se superponía sobre los mecanismos de varias jurisdicciones y la omnipresencia de la supervisión religiosa, aseguró el control de movimientos de cualquier persona detenida, en espera de juicio o de sentencia, que hubiera pasado por la cárcel o que tuviera abierto alguno de los procedimientos simultáneos de depuración, masonería, responsabilidades políticas.... La exigencia de avales y de certificados llevó a una corrupción generalizada y a un mercado negro de papeles paralelo al de alimentos. Y aquí es donde más pesó el aislamiento social promovido por la política represiva del régimen, que se extendió hasta formas más sutiles como las denominadas suscripciones patrióticas y todo tipo de cuestaciones vecinales. Una política así diseñada desembocaba forzosamente en la muerte civil de los afectados. Los antecedentes penales, la inscripción en

Oficina do Historiador, Porto Alegre, EDIPUCRS, v. 8, n. 1, jan./jun. 2015, p. 117-133. 
el registro de penados y rebeldes, los distintos ficheros de inhabilitación profesional y para desempeñar cargos públicos, la incautación de bienes, las multas, etc. hacían imposible volver a la vida anterior a la guerra. Desempeñar cualquier actividad económica, viajar, hasta solicitar el carnet de conducir, y por supuesto, sortear la depuración laboral, exigía el permiso de la autoridad local o gubernativa y eso podía dar lugar a una nueva investigación. Ninguno de los mecanismos de revisión de las condenas, civiles o penales, llegaron a articularse realmente hasta entrados los años 50, pero para entonces el miedo ya había paralizado parcial o totalmente a buena parte de la sociedad española.

\section{Referencias bibliográficas}

CASTEJón, F. Génesis y breve comentario del Código Penal de 1944. Madrid: Reus, 1946.

FOUCAULT, M. La verdad y las formas jurídicas. Barcelona: Gedisa, 1999. GÓMEZ BRAVO, G. Conversión: la iglesia y la política penitenciaria de posguerra. Historia social, 74. 2014. pp 63-98.

Crimen y castigo: cárceles, delito y violencia en la España del siglo XIX. Madrid: Catarata, 2005.

. La redención de penas: la formación del sistema penitenciario franquista. 19361950. Madrid: Catarata, 2007.

. Los delitos y las penas: La ciudad judicial y penitenciaria - Alcalá de Henares, 1800-1900. Madrid: Fundación Colegio del Rey, 2006.

GÓMEZ BRAVO, G.; MARCO, J. La obra del miedo: Violencia y sociedad en la España franquista. Barcelona: Península, 2011.

HERRERO HERRERO, C. España penal y penitenciaria: Historia y actualidad. Madrid: Instituto de Estudios de la Policía, 1985.

JUDT, T. Sobre el olvidado siglo XX. Madrid: Taurus, 2008.

LA NORMATIVA LABORAL Y PENITENCIARIA. Situación y desarrollo. Madrid: Organismo autónomo trabajos penitenciarios, 1982.

MARTÍNEZ MARTÍN, J. La lectura en la España contemporánea: lectores, discursos y prácticas de lectura. Ayer, n. 58, 2005, p. 15-34.

MARTÍNEZ RUS, A. La represión cultural: libros destruidos, bibliotecas depuradas y lecturas vigiladas. In: ARÓSTEGUI, J. (coord.). Franco: la represión como sistema. Madrid: Flor del Viento, 2011. p. 365-415.

OBRA DE LA REDENCIÓN DE PENAS (1943-44). Alcalá de Henares: Imprenta de Talleres Penitenciarios, 1944.

OBRA DE LA REDENCIÓN DE PENAS (1944-45). Alcalá de Henares: Imprenta de Talleres Penitenciarios, 1945.

OBRA PATRONATO REDENCIÓN PENAS POR EL TRABAJO. Memoria Año 1942. Imprenta Talleres Penitenciarios Alcalá, 1943.

PÉREZ DEL PULGAR, J. A. La solución que España da al problema de sus presos políticos. Valladolid: Publicaciones Redención, 1939.

RODRÍGUEZ DEVESA, J. Ma. Derecho penal. Parte general. Madrid: Reus, 1973.

Oficina do Historiador, Porto Alegre, EDIPUCRS, v. 8, n. 1, jan./jun. 2015, p. 117-133. 
SÁNCHEZ BIOSCA, V. (dir.). Materiales para una iconografía de Francisco Franco. Archivos de la Filmoteca, n. 42-43, 2002-2003.

SÁNCHEZ DE MUNIAIN, J. M. Concepto y teoría de la propaganda. Arbor, n. 17, sep.oct./1946, p. 205-246.

SÁNCHEZ GARCÍA, R. Morfología del texto y producción de sentido en la lectura. Ayer, n. 58, 2005. p. 57-86.

ARTIGO ENVIADO EM: 16/09/2014 ACEITO PARA PUBLICAÇÃO EM: 01/11/2014 